\title{
Estimation and confirmation of adsorption behavior of acrylic polymer on alumina from a molecular chemistry standpoint of adipic acid adsorption
}

\author{
Kouichi NAGATA and Hitoshi YAMAMOTo*
}

\author{
Process Design Department, Corporate R\&D Division for Components \& Devices, Kyocera Corporation, \\ 6, Takeda Tobadono-cho, Fushimi-ku, Kyoto 612-8501 \\ *Department for the Administration of Safety and Hygiene, Laboratory of Chemistry for Environment and Safety, Osaka University, \\ 1-1, Yamadaoka, Suita, Osaka 565-0871
}

\begin{abstract}
Adsorption of a low molecular carboxylic acid (adipic acid) on alumina was studied at molecular chemistry standpoint to estimate adsorption behavior of an acrylic polymer containing carboxylic acid group in water-base system. By the zeta potential measurement, adipic acid adsorbs on alumina chemically. The maximum amount of adsorption of adipic acid was observed at $\mathrm{pH}$, which is close to $\mathrm{pKa}_{1}\left(\mathbf{4 . 4 1 )}\right.$ and $\mathrm{pKa} \mathrm{a}_{2}(\mathbf{5 . 2 8})$ of adipic acid. In the region over $\mathrm{pH}$, the adsorbed amount decreased monotonously with increase of $\mathrm{pH}$. Adsorption behavior of adipic acid is considered by investigating both surface species distribution on alumina $\left(\mathrm{AlOH}_{2}^{+}, \mathrm{AlOH}, \mathrm{AlO}^{-}\right)$, and species distribution diagram of adipic acid $\left(\mathrm{H}_{2} X, \mathrm{HX}^{-}, \mathrm{X}^{2-} ; \mathrm{X}^{-}\right.$ $\left.-\mathrm{OCOC}_{4} \mathrm{H}_{8} \mathrm{COO}-\right)$ at various $\mathrm{pH}$. It is supposed that amount of adsorbed adipic acid on alumina is maximum, because the electrostatic attraction between a positive charge of alumina surface and a negative charge of adipic acid is large. By FT-IR analysis of adsorbate, alumina surface reaction with adipic acid produces outer-sphere complex at pH higher than pKa1 of adipic acid. The occupation area of one adipic acid molecule that was calculated from the amount of adsorption agreed with the molecule area estimated by chem-3D simulator. Adipic acid is supposed to be adsorbed on alumina surface perpendicularly in a single molecule layer. Adsorption of acrylic resin on alumina in alkali side was predicted from the knowledge of adsorption behavior of adipic acid. Furthermore, properties of polymer solution, suspension behavior and green sheet were estimated and confirmed. It is found that a molecular chemistry study of adsorption of a low molecular weight carboxylic acid can be adapted to polymer system. (C2008 The Ceramic Society of Japan. All rights reserved.
\end{abstract}

Key-words : Adipic acid, Alumina, Water-base, Adsorption behavior, FT-IR spectra, Suspension, Green sheet

[Received June 23, 2008; Accepted September 11, 2008]

\section{Introduction}

The present work was commenced to study the role of polymer binders in water-base green sheets for fine ceramics. Green sheets must meet several requirements: dimensional stability, uniform packing degree, sufficient flexibility for handling and machining, absence of defects, sufficient adhesion for lamination. The most important requirement is uniform shrinkage after sintering. There is high correlation in dimensions of ceramics after sintering and packing degree of green sheets, which is the particularly important item in the production of highly precise products.

Production of water-base green sheets which is eco-friendly process has been strongly expected. However, at present manufacture of suspensions for green sheets is mainly produced in a non-aqueous system. Productions of ceramic green sheets in a water-base system are limited to some products. The reason is that this production is inferior in dispersion characteristics and drying characteristics. And another reason is because water-base green sheets have poor adhesiveness in lamination, sensitiveness to humidity and poor thermolysis characteristics. Furthermore, control method of the packing degree of green sheets to make products in high accuracy has not been studied and established. It is said that the packing degree of green sheets is connected with a flow characteristic of suspension, but basic science has not been established on stability of ceramic particles in suspension.
In suspension, ceramic particles are usually stabilized by adsorption of polymer. The adsorption mechanism of polymers onto ceramic particles is an essential issue to produce fine ceramic products. Therefore I clarified adsorption mechanism of a polymer to ceramic particles by a scientific approach and aimed at making stable suspensions. Prior to studying the polymer adsorption mechanism, adsorption behavior of a dicarboxylic acid (adipic acid) on $\alpha$-alumina was clarified for a molecular chemistry standpoint.

A lot of studies about adsorption of a carboxylic acid with ceramics have been reported. ${ }^{1)-7)}$ The focus has been on interaction between organic substances and metal (hydro) oxides. FT-IR is a popular tool for investigating processes at the solid/aqueous interface. ${ }^{8)-14)}$ Kumar et al. ${ }^{15)}$ confirmed the chemisorption of oleic acid on the sillimanite by zeta-potential, adsorption isotherm and FTIR studies. Arenas et al. ${ }^{16)}$ reported two symmetric and asymmetric $\nu_{\mathrm{C}-\mathrm{O}}$ bands were explained by the cooperative and opposing movements of the rotated carboxylic groups in the FT-IR and Raman spectroscopic investigation. Klug et al. ${ }^{17)}$ indicated that outersphere complex and inner-sphere complex were formed by investigation of surface complexation of phthalic acid/phthalate on $\gamma$ aluminum oxide by IR and Raman spectroscopy. Szaraz et al. ${ }^{18)}$ also investigated the adsorption mechanism of azelaic acid on synthetic $\gamma$-aluminium oxide surfaces using FT-IR spectroscopy. They reported that three main surface complexes were found on the surface of the $\gamma$-alumina at low $\mathrm{pH}$ in aqueous, while at high 
$\mathrm{pH}$ one of them namely the outer-sphere complex dominates. $\gamma$ alumina has a large surface area of $150 \mathrm{~m}^{2} / \mathrm{g}$, whereas surface area of $\alpha$-alumina used in single substrate and multilayer package is lower than $10 \mathrm{~m}^{2} / \mathrm{g}$. Adipic acid was adopted to an example of a low molecular carboxylic acid. Adsorption reaction of an adipic acid with $\alpha$-alumina was investigated in this study.

It is well known that the viscosity of poly (carboxylic acid) changes with $\mathrm{pH} .{ }^{19)}$ Poly (acrylic acid) is a representative of poly (carboxylic acid). Production of water-base green sheets is usually done in alkali side, because corrosion of container and plumbing as well as the bad influence to the human body and environment are problems for production in acid side. The relation between viscosity of poly (acrylic acid) and $\mathrm{pH}$ was investigated in alkali side to predict a viscosity change of polymers containing carboxylic acid. From the results of adsorption of adipic acid on alumina and the viscosity change of a PAA solution, adsorption mechanism of acrylic polymers containing carboxylic acid on alumina was estimated. Furthermore adsorption behavior of acrylic resin $\mathrm{P}-4$, properties of suspension and green sheet prepared with $\mathrm{P}-4$ are confirmed.

\section{Experiments}

\subsection{Materials}

Adipic acid (Wako Pure Chemical Ind., Ltd.) that was used is a best quality chemical reagent. $\alpha$-alumina powder was AL160SG (Showa Denko Corp.), an average particle size of $0.6 \mu \mathrm{m}$ and the surface area of $6.0 \mathrm{~m}^{2} / \mathrm{g}$. The point of zero charge of this sample was $\mathrm{pH}$ 8.5. Poly (acrylic acid) was denoted as PAA (Mw $1,080,000$, Aldrich). The polymer (P-4, LION Corp.) was a copolymer of an acrylic ester and acrylic acid with acid value of $20 \mathrm{mgKOH} / \mathrm{g}, T_{\mathrm{g}}$ of $-15^{\circ}$ Celcius, Mw of 140,000 and $\mathrm{pH} 7.0$. Mw of polymers was determined in THF by gel permeation chromatography. $T_{\mathrm{g}}$ of polymers were calculated by the weight ratio and $T_{\mathrm{g}}$ of each homo polymer. $\mathrm{P}-4$ was chosen for next reasons, such as flexibility of polymer film, dispersibility of ceramic particles, thermolysis and dissolution characters to an ammonium hydroxide solution.

\subsection{Suspension and green sheets procedure}

Amount of added polymer was fixed to a constant ratio; solid polymer/alumina is $6 / 100$.

Alumina powder $(500 \mathrm{~g})$, polymer solutions (120 g) and the distilled water $(125 \mathrm{~g})$ were mixed with alumina media $(500 \mathrm{~g})$ for $20 \mathrm{~h}$ by a ball-milling method. The $\mathrm{pH}$ of polymer solutions was adjusted to $6.8,7.4,7.8,8.3,9.2$ and 9.9 by using $6 \mathrm{wt} \%$ ammonium hydroxide solution. The concentration of all polymer solutions were $25 \mathrm{wt} \%$. Six suspensions were prepared with these polymer solutions. Suspensions were cast on PET films and dried at $80^{\circ}$ Celcius for $1 \mathrm{~h}$.

\subsection{Measurements}

(1) Zeta potential of alumina: Zeta potential value of alumina was measured by Light Scattering Photometer (Otsuka electronics Corp.), which was determined from the electrophoretic mobility value using the Helmholtz-Smoluchowski equation. To measure a zero point of charge $(\mathrm{zpc})$ of the alumina, $5 \mathrm{wt} \%$ alumina suspension $(0.01 \mathrm{~g})$ was dropped into $10 \mathrm{dL}$ water. $5 \mathrm{wt} \%$ alumina suspension $(0.01 \mathrm{~g})$ was conditioned with $10 \mathrm{mM}$ adipic acid solutions that were predetermined to various $\mathrm{pH}$. At the end of conditioning, $\mathrm{pH}$ of solutions was measured. On the other hand, $5 \mathrm{wt} \%$ alumina suspension $(0.01 \mathrm{~g})$ was mixed with $10 \mathrm{dL}$ water containing $0.05 \mathrm{mM} \mathrm{P}-4$. The $\mathrm{pH}$ of suspensions were adjusted with $0.1 \mathrm{M} \mathrm{HCl}$ in acidity side and with $0.1 \mathrm{M} \mathrm{NaOH}$ in alkali side.

(2) Adsorption of organic substrates: Amount of adsorbed organic substrates was determined by measuring the differential concentration of organic substrates in the supernatant solution and the initial polymer solution. The concentration of adipic acid solution used for an experiment is $10 \mathrm{mM}$. This solution was divided into nine containers by $100 \mathrm{~g}$ each, then $\mathrm{pH}$ of those solutions ware adjusted to $2,3,4,5,6,7,8,9$ and 10. Dry alumina powder $(0.5 \mathrm{~g})$ was added in each poly container and conditioned for $1 \mathrm{~h}$. After equilibrium, each suspension was separated by a centrifuge in a condition of $10,000 \mathrm{rpm}$ for $1 \mathrm{~h}$. In the case of suspensions with $\mathrm{P}-4$, suspensions were diluted to $10 \mathrm{wt} \%$ in order to be separated well.

(3) FT-IR spectroscopy: FT-IR spectra were collected with Nicolet 4700 FT-IR spectrometer (Thermo Electron Corp.) which was equipped with a DTOS detector. Sediments separated by a centrifuge were dried at $80^{\circ}$ Celcius and were analyzed with the attenuated total reflection (ATR) technique.

(4) Rheological measurement: Steady shear flow curves were obtained using a rotary viscometer Rheometer MCR301 (Physica Corp.).

Viscosity, $\eta(\mathrm{Pa} \cdot \mathrm{s})$, was determined using the relationship:

$$
\eta=S / D
$$

Where

$S$ : Shear stress $(\mathrm{Pa}), D$ : Shear rate $\left(\mathrm{s}^{-1}\right)$.

Viscosities of alumina suspension and polymer solution were measured with a shear rate from 1 to $210 \mathrm{~s}^{-1}$.

(5) Packing degree of green sheets: The packing degree of green sheets was calculated by Eq. (2).

$$
D=\frac{100 \times W}{\rho_{\mathrm{a}} \times(1+b) \times V}
$$

Where

$D$ : the packing degree of green sheets (wt $\%), W$ and $V$ : weight $(\mathrm{g})$ and volume $\left(\mathrm{cm}^{3}\right)$ of a sample $(30 \times 35 \times 0.6 \mathrm{~mm}), \rho_{\mathrm{a}}$ : true specific gravity of alumina $(-), b$ : the ratio of added polymer content and alumina (-).

\section{Results and discussion}

\subsection{Adsorption of adipic acid on $\alpha$-alumina}

Zeta potential measurements of alumina with adipic acid and without adipic acid were conducted at different $\mathrm{pH}$ values. The results were shown in Fig. 1. From the results of alumina, the zpc of alumina was observed at $\mathrm{pH} 8.5$. At $\mathrm{pH}$ below 8.5 the surface

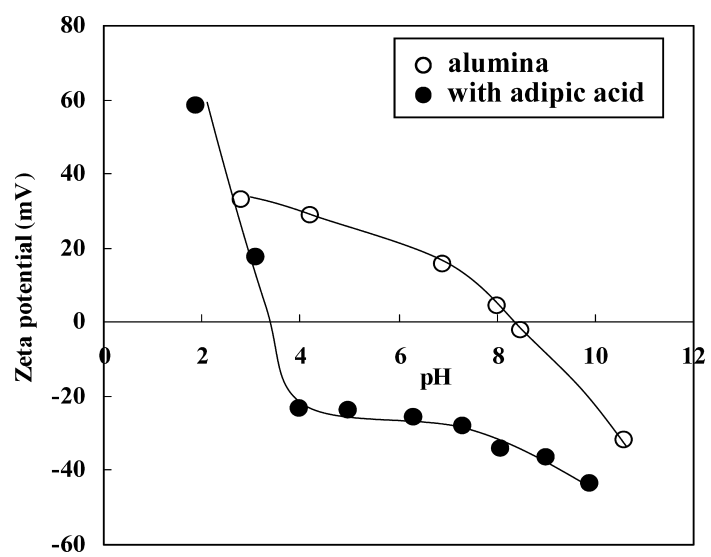

Fig. 1. Zeta potential of $\alpha$-alumina with adipic acid. 
of alumina is positively charged, and that is negatively charged at $\mathrm{pH}$ more than 8.5. The zpc value was found to shift to lower $\mathrm{pH}$ (3 to 4) by addition of adipic acid. In the absence of specific adsorption, there should not be any shift in zpc. The characteristic shift in zpc is attributed to the chemisorption of adipic acid in the inner region of double layer. Similar characteristic shift in zpc observed in the case of rutile-oleate ${ }^{20)}$ and alumina-oleate ${ }^{21)}$ was attributed to chemisorption. In addition, a result of the zeta potential measurement of alumina prepared with adipic acid solution of $30 \mathrm{mM}$ was equal with the result of alumina prepared with adipic acid solution of $10 \mathrm{mM}$ (the figure was omitted).

Adsorption of adipic acid on alumina surface was measured at different conditions of $\mathrm{pH}$ and shown in Fig. 2. Initial concentration of adipic acid solution was $10 \mathrm{mM}$. It is apparent that the maximum adsorption of adipic acid on alumina was obtained at $\mathrm{pH}$ 5.0. At $\mathrm{pH}$ over 5, the amount of adsorbed adipic acid decreased monotonously as $\mathrm{pH}$ of solutions increased. This behavior is similar to that of sillimanite with oleate. ${ }^{15)}$ From the amount of adsorption at $\mathrm{pH} 5.0$, an occupation area of one adipic acid molecule is calculated. When adipic acid is presumed to adsorb in a monolayer on the surface of alumina, the occupation area is $0.10 \mathrm{~nm}^{2}$. The molecular structure of adipic acid is simulated by chem.3D. Adipic acid is assumed the rectangular solid which has carboxyl groups in both ends. The lengths of side are $0.23(X)$, $1.08(Y)$ and $0.47 \mathrm{~nm}(Z)$. The area of a rectangle $(X-Z)$ is $0.11 \mathrm{~nm}^{2}$ that almost corresponds with the occupation area calculated from the amount of adsorption. From these results, it is

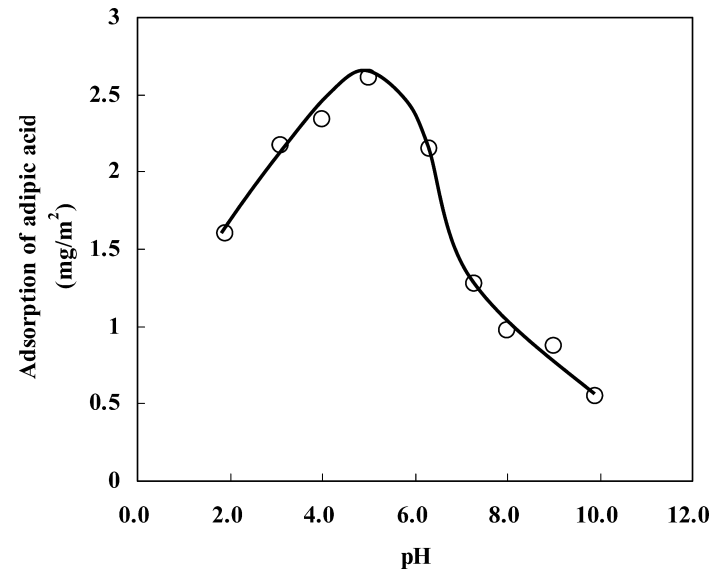

Fig. 2. Adsorption of adipic acid on $\alpha$-alumina. thought that adipic acid adsorbs on the surface of alumina perpendicularly in a state of a single molecule layer.

FT-IR spectroscopy of sediments at $\mathrm{pH} 1.9, \mathrm{pH} 5.0$ and $\mathrm{pH}$ 9.9 is shown in Fig. 3. The most interesting part of the spectra is between $1350 \mathrm{~cm}^{-1}$ and $1750 \mathrm{~cm}^{-1}$. In that area the carbonyl stretching frequency $\left(1690 \mathrm{~cm}^{-1}\right)$, the asymmetric $(1550-1615$ $\mathrm{cm}^{-1}$ ) and the symmetric $\left(1400-1480 \mathrm{~cm}^{-1}\right)$ stretching frequencies of the carboxylic group of the adipic acid as well as the $\mathrm{CH}_{2}$ bending vibrations can be found. In the spectrum of sediment at $\mathrm{pH} 1.9$ the distinct absorption bands can be seen at 1690, 1585 , and $1560 \mathrm{~cm}^{-1}$. The band at $1690 \mathrm{~cm}^{-1}$ can be assigned to the stretching vibration of the carbonyl group. Because the $\mathrm{pKa}$ and $\mathrm{pKa} \mathrm{a}_{2}$ of adipic acid is 4.41 and 5.28 respectively, the adipic acid is not deprotonated at $\mathrm{pH} 1.9$. The bands at $1585 \mathrm{~cm}^{-1}$ and at $1560 \mathrm{~cm}^{-1}$ can be assigned to the asymmetric stretching vibration of the carboxylic acid. In the spectrum of sediment at $\mathrm{pH}$ 5.0 the band at $1690 \mathrm{~cm}^{-1}$ is weak, indicating adipic acid is deprotonated substantially. At $\mathrm{pH}$ values above the first $\mathrm{pKa}$ value of adipic acid only the asymmetric stretching vibration of carboxylic acid $\left(1560 \mathrm{~cm}^{-1}\right)$ can be observed. Comparing the spectra of sediments at $\mathrm{pH} 5.0$ and at $\mathrm{pH} 9.9$, big difference can be recognized in the adsorbed amounts.

For better illustration of the nature of adsorption, a species distribution diagram on alumina surface as a function of $\mathrm{pH}^{15)}$ was adopted (shown in Fig. 4).

Surface species of alumina shown in Fig. 4 clearly illustrate that the positively charged $\mathrm{AlOH}_{2}{ }^{+}$exists in the acidic range and negatively charged $\mathrm{AlO}^{-}$sites dominate above $\mathrm{pH}$ 8.0. At $\mathrm{pH}$ 8.0, neutral molecules of $\mathrm{AlOH}$ are dominant. In Fig. 5 species distribution diagram of adipic acid as a function of $\mathrm{pH}$ was shown. It is known that adipic acid forms various species such as undissociated acid $\left(\mathrm{H}_{2} X\right)$, adipate ion $\left(\mathrm{HX}^{-}\right.$and $X^{2-}$; $X$ : $-\mathrm{OCOC}_{4} \mathrm{H}_{8} \mathrm{COO}-$ ). The following thermodynamic equilibrium constants were considered in constructing a species distribution diagram of adipic acid species: Mole ratio of species was calculated by Eq. (3). ${ }^{22)}$ Where $\mathrm{K}_{1}, \mathrm{~K}_{2}$; acid dissociation constant.

$$
\begin{aligned}
\mathrm{aH}_{2} X & =\frac{\left[\mathrm{H}^{+}\right]^{2}}{\left[\mathrm{H}^{+}\right]^{2}+\left[\mathrm{H}^{+}\right] \mathrm{K}_{1}+\mathrm{K}_{1} \cdot \mathrm{K}_{2}} \\
\mathrm{aH} X^{-} & =\frac{\left[\mathrm{H}^{+}\right] \mathrm{K}_{1}}{\left[\mathrm{H}^{+}\right]^{2}+\left[\mathrm{H}^{+}\right] \mathrm{K}_{1}+\mathrm{K}_{1} \cdot \mathrm{K}_{2}} \\
\mathrm{a} X^{2-} & =\frac{\mathrm{K}_{1} \cdot \mathrm{K}_{2}}{\left[\mathrm{H}^{+}\right]^{2}+\left[\mathrm{H}^{+}\right] \mathrm{K}_{1}+\mathrm{K}_{1} \cdot \mathrm{K}_{2}}
\end{aligned}
$$

In the acidic region, $\mathrm{H}_{2} X$ and $\mathrm{HX}^{-}$are the dominant species,

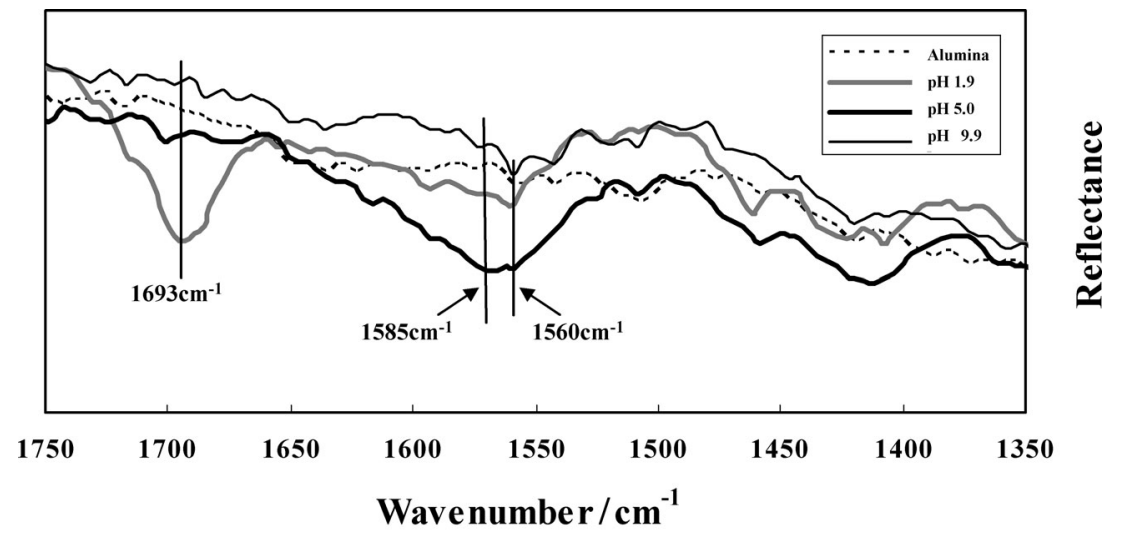

Fig. 3. FT-IR spectra of $\alpha$-alumina with adipic acid. 


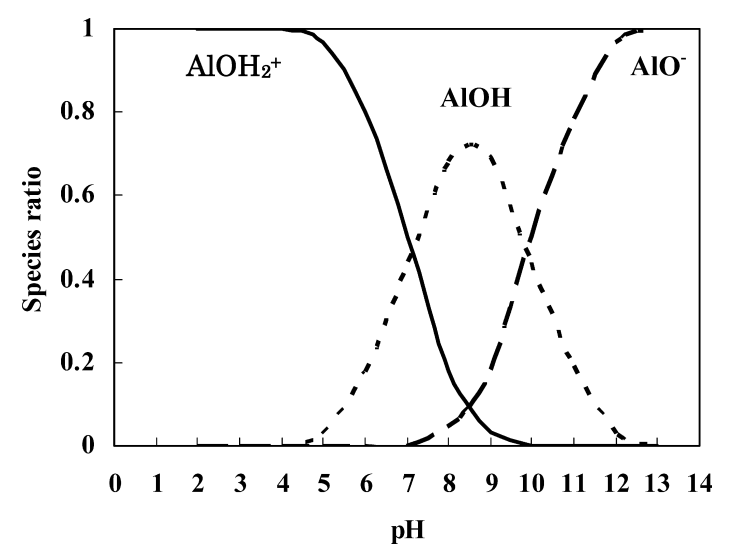

Fig. 4. Distribution diagram of surface species on alumina as a function of $\mathrm{pH}$.

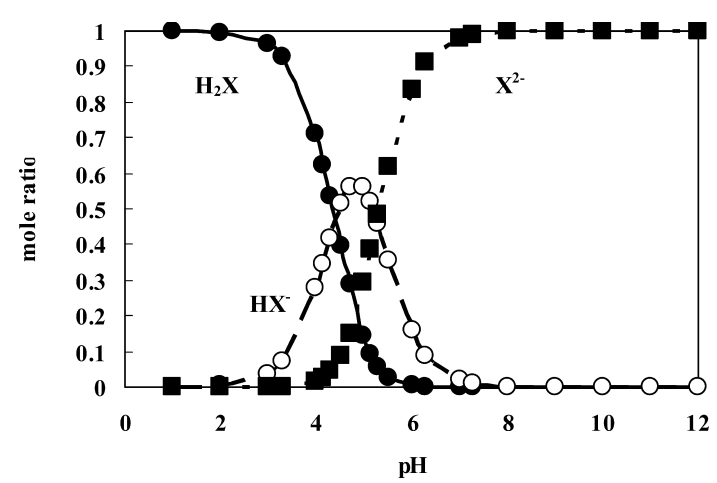

Fig. 5. Species distribution diagram of adipic acid as a function of $\mathrm{pH}$.

whereas species $X^{2-}$ exists in the basic region. It is noted that the concentration of $\mathrm{HX}^{-}$species is maximum around $\mathrm{pH}$ 5. The adsorption maximum of adipic acid on alumina around $\mathrm{pH} 5$ could be due to electrostatic interaction between $\mathrm{H} X^{-}$and $\mathrm{AlOH}_{2}{ }^{+}$sites. It is thought that adipic acid adsorbs on the surface of alumina perpendicularly in a state of a single molecular layer because of electrostatic interaction between monovalent ions. Because electrostatic repulsion between $\mathrm{X}^{2-}$ and $\mathrm{AlO}^{-}$is dominant at $\mathrm{pH}$ over 9 , it is supposed that the amount of adsorbed adipic acid is small. Klug et al. ${ }^{17)}$ investigated the adsorption of phthalate on $\gamma$-alumina and reported that FT-IR band around $1560 \mathrm{~cm}^{-1}$ is originating from the asymmetric carboxylate motions of the outer-sphere complex. On the basis of the assumed alumina surface sites and adsorbing species on alumina at $\mathrm{pH} 5$, the suggested model of an adipic acid complex on alumina surface is shown in Fig. 6. In Table 1 species of alumina and adipic acid as a function of $\mathrm{pH}$ are shown.

\subsection{Effect of pH on viscosity of poly (acrylic acid) solution}

The viscosity of $2 \mathrm{wt} \%$ PAA solution as a function of $\mathrm{pH}$ is shown in Fig. 7. Viscosity does not change under a value of $\mathrm{pH}$ 5 too much, but it suddenly rises between $\mathrm{pH} 6$ from $\mathrm{pH} 5$ and it increases gradually at $\mathrm{pH}$ over 6 . Because the calculated $\mathrm{pKa}$ value of PAA is 4.5, sudden rise between $\mathrm{pH} 6$ from $\mathrm{pH} 5$ is caused by dissociation of carboxylic acid groups. As $\mathrm{pH}$ increases, the dissociated carboxylate ion is thought to become large and expanded condition. This result indicates that PAA is a kind of typical polyelectrolytes.

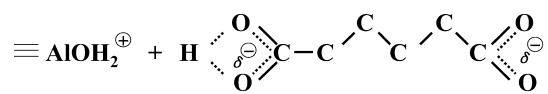

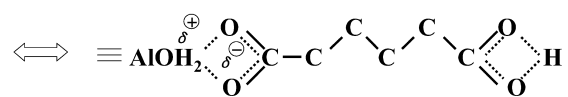

Fig. 6. Adsorption model of adipic acid on alumina around at $\mathrm{p} K \mathrm{a}_{1}$ and $\mathrm{p} K \mathrm{a}_{2}$.

Table 1. Species of Alumina and Adipic Acid as a Function of $\mathrm{pH}$

\begin{tabular}{|c|c|c|c|c|c|c|c|c|c|}
\hline \multirow{2}{*}{$\begin{array}{l}\text { Species of alumina } \\
\text { and adipic acid }\end{array}$} & \multicolumn{9}{|c|}{$\mathrm{pH}$} \\
\hline & 23 & 4 & 5 & 6 & 7 & 8 & 9 & 10 & 11 \\
\hline \multicolumn{10}{|l|}{$\mathrm{AlOH}_{2}{ }^{+}+\mathrm{H}_{2} X$} \\
\hline $\mathrm{AlOH}_{2}^{+}+\mathrm{H} X^{-}$ & Attractive & 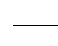 & & & & & & & \\
\hline $\mathrm{AlOH}_{2}^{+}+X^{2-}$ & Attra & ctive & & & & & & & \\
\hline $\mathrm{AlOH}+X^{2-}$ & & & & & & & & & \\
\hline $\mathrm{AlO}^{-}+X^{2-}$ & & & & & & $\mathrm{pu}$ & ive & & \\
\hline
\end{tabular}

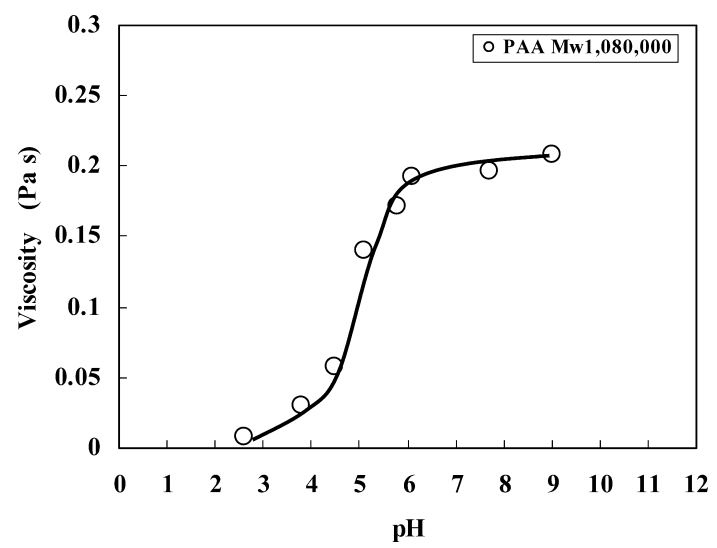

Fig. 7. Viscosity of $2 \mathrm{wt} \%$ PAA solution as a function of $\mathrm{pH}$.

\subsection{Estimation of adsorption behavior of acrylic resin containing carboxylic acid on $\alpha$-alumina}

Production of suspension for green sheets in water-base system is limited in alkali side, because there are many problems in production in acidity side such as corrosion of container and plumbing, bad influence to human body and environments. From the results of adipic acid adsorption behavior on alumina and the viscosity increase of PAA solution in alkali side $(\mathrm{pH}>7)$, adsorption behavior of acrylic resin containing a carboxylic acid on $\alpha$-alumina is estimated. It is supposed that the viscosity of acrylic resin containing a carboxylic acid increases with increase of $\mathrm{pH}$ in alkali side. By the electrostatic repulsion between a negative charge of alumina surface sites and a negative charge of calboxylate ion, the amount of adsorbed polymer decreases with increase of $\mathrm{pH}$ in alkali side. Estimation of properties of polymer solution, suspension behavior and green sheet is shown in Table 2. The steric stabilization by adsorption of polymers is assumed to be effective for dispersion of alumina. Because amount of adsorbed polymer decreases with increase of $\mathrm{pH}$, dispersion characteristics should become bad, suggesting that a tendency of a shear-thinning flow behavior becomes strong. The packing 
degree of green sheets is thought to be low because cohesion structure of alumina particles in poor dispersed suspension is maintained during drying. As the amount of free polymer (not adsorbed polymer) increases with increase of $\mathrm{pH}$, the resultant green sheet can have a large strain (elongation).

\subsection{Confirmation of adsorption behavior of acrylic resin $\mathrm{P}-4$, properties of suspension and green sheet}

$\mathrm{P}-4$ is adopted for an acrylic resin containing a carboxylic acid. Adsorption behavior of $\mathrm{P}-4$ on alumina, rheological behavior of suspension and characteristics of green sheets are investigated. In Fig. 8 zeta-potential of alumina prepared with $0.05 \mathrm{mM} \mathrm{P}-4$ solu-

Table 2. Estimation of Properties of Polymer Solution, Suspension and Green Sheet

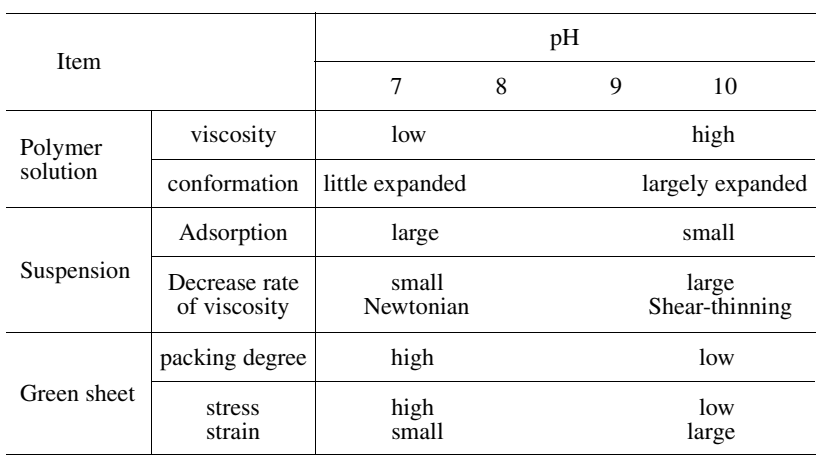

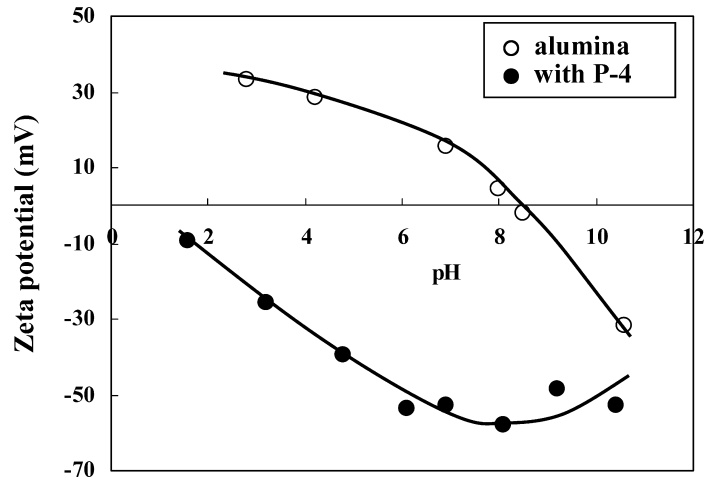

Fig. 8. Zeta potential of $\alpha$-alumina with $\mathrm{P}-4$. tion is shown. Zpc of alumina is shifted to lower $\mathrm{pH}$ as well as adipic acid, however zeta potential at $\mathrm{pH} 1.6$ is negative still. Because $\mathrm{pH}$ of $\mathrm{P}-4$ solution is 6.8 at first, it is thought that carboxylate ion in expanded structure is hard to be neutralized by 0.1 $\mathrm{M} \mathrm{HCl}$ in the acidity side. The amount of adsorbed $\mathrm{P}-4$ on alumina and packing degree of green sheets vs $\mathrm{pH}$ of $\mathrm{P}-4$ solution are shown in Fig. 9. As pH of $\mathrm{P}-4$ solution increases, amount of adsorbed $\mathrm{P}-4$ on alumina decreases in alkali side as well as adipic acid. Packing degrees of green sheets decrease with increase of $\mathrm{pH}$ of $\mathrm{P}-4$ solution. The $\mathrm{pH}$ of the suspension becomes 7.7 when polymer solution of $\mathrm{pH} 6.8$ is mixed with alumina. Similarly suspensions of $\mathrm{pH}$ are obtained 8.3, 8.5, 8.6, 9.2 and 9.5 by mixing polymer solutions of $\mathrm{pH} 7.4,7.8,8.3,9.2$ and 9.9 with alumina respectively. The $\mathrm{pH}$ of the ion-exchanged water which was used for an experiment is 6.3, and the $\mathrm{pH}$ of alumina suspension mixed with water is 8.6. The reason why $\mathrm{pH}$ of alumina suspension with and without P-4 increases is regarded as elution of a small amount of sodium ion in alumina.

FT-IR spectroscopy of polymer film of $\mathrm{P}-4$ and the sediment that was obtained by centrifuge of suspension containing $\mathrm{P}-4$ and alumina is shown in Fig. 10. Both samples used polymer solution of $\mathrm{pH}$ 6.8. Data of samples that was obtained by $\mathrm{pH} 9.9$ polymer solution were omitted because a difference was not observed with $\mathrm{pH}$ 6.8. A peak of a carbonyl group of acrylic acid is not seen in $1710 \mathrm{~cm}^{-1}$ from $1700 \mathrm{~cm}^{-1}$ with a polymer film. This reason is because that $\mathrm{P}-4$ contains a little amount of acrylic acid. In addition, a peak by hydrogen bonding in a molecule of a carbonyl group is observed at $1650 \mathrm{~cm}^{-1}$. On the other hand, this peak disappears in the sediment, and the peak of is $(\mathrm{C}=\mathrm{O})$ shifts to 1729

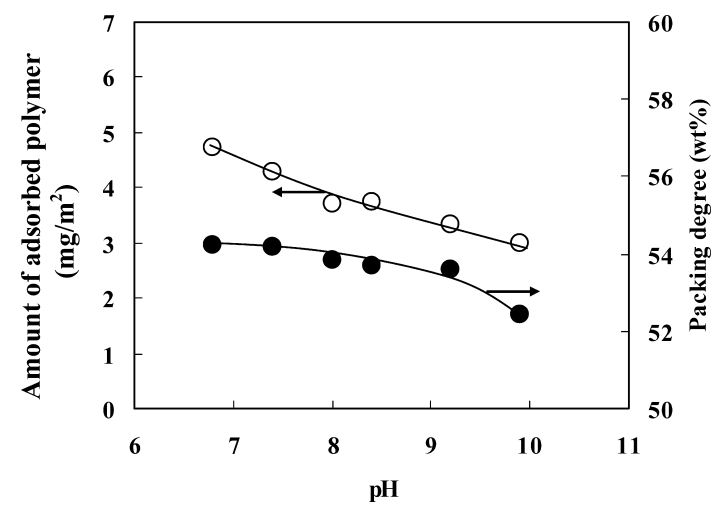

Fig. 9. Adsorption of $\mathrm{P}-4$ on $\alpha$-alumina.

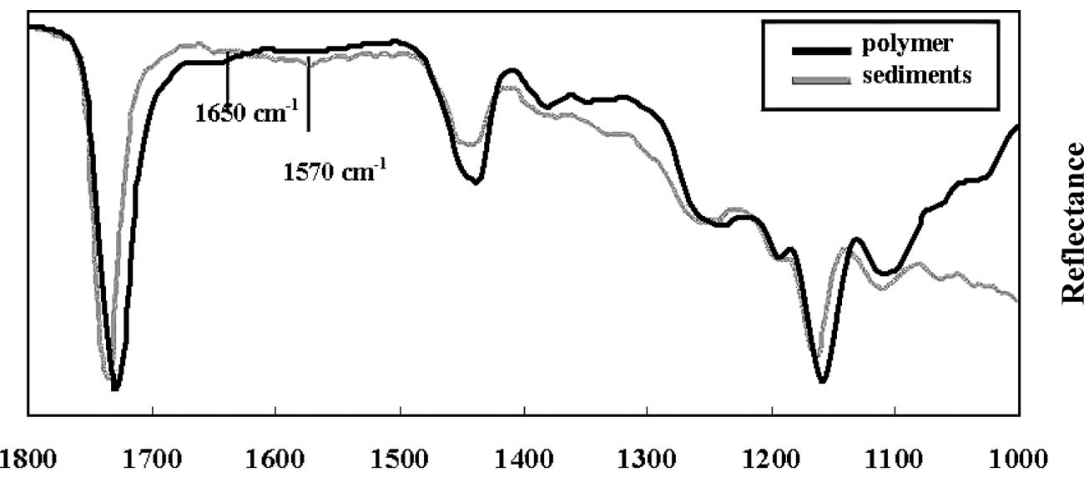

Wavenumber $/ \mathrm{cm}^{-1}$

Fig. 10. FT-IR spectra of polymer film and sediments of suspension. 


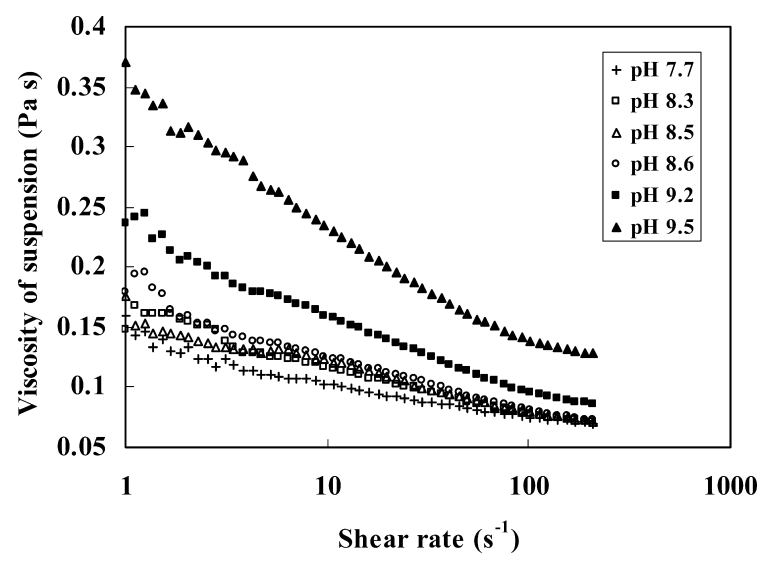

Fig. 11. Viscosity of suspension and shear rate.

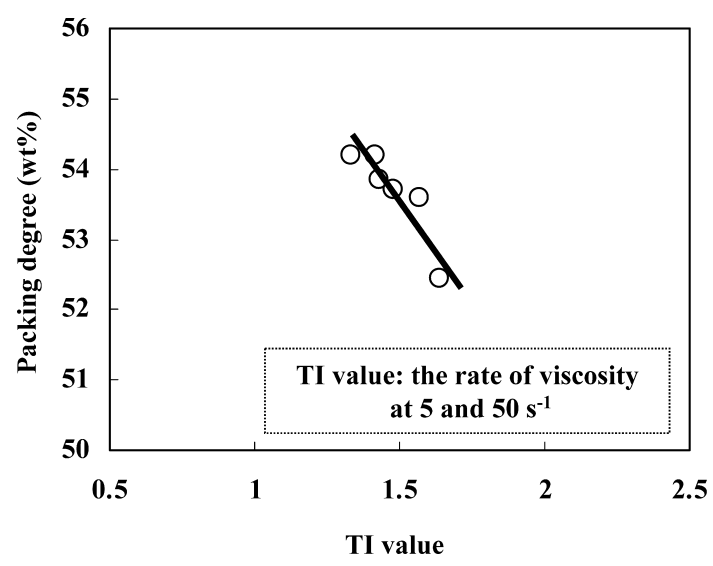

Fig. 12. TI value and packing degree of green sheet.

$\mathrm{cm}^{-1}\left(10 \mathrm{~cm}^{-1}\right.$ higher than that of polymer film). It is thought that the carbonyl group which took resonance structure in a molecule by hydrogen bonding takes some new resonance structure with alumina. A peak at $1570 \mathrm{~cm}^{-1}$ is seen in the sediment; however this peak is so slight to be judged a complex with alumina.

The viscosity of 6 suspensions prepared with these polymer solutions are shown as a function of $\mathrm{pH}$ in Fig. 11. The decrease rate of viscosity for shear rate increases as $\mathrm{pH}$ of $\mathrm{P}-4$ solution increases. In other word, a shear-thinning flow behavior is observed remarkably in higher $\mathrm{pH}$. The packing degree of green sheets and TI value as a function of $\mathrm{pH}$ of suspension are shown in Fig. 12. As the $\mathrm{pH}$ of suspensions increases, the TI value of suspensions increases and the packing degree of green sheets decreases. The TI (Thixotropic Index) value is the ratio of viscosity at shear rate of 5 and $50 \mathrm{~s}^{-1}$. This value indicates the flow characteristics of suspension. As the TI value approaches 1, the tendency of a Newtonian flow behavior becomes stronger; and a high value shows a strong shear-thinning flow behavior. Based on this result, it is suggested that cohesion structure of alumina particles is maintained during drying in the system using suspension of $\mathrm{pH} 9.5$.

\section{Conclusions}

The zpc value of alumina was found to shift to lower $\mathrm{pH}$ between 3 and 4 in the presence of adipic acid, indicating the existence of chemisorption. The maximum adsorption of adipic acid on alumina was obtained at $\mathrm{pH} 5$ (around two $\mathrm{pKa}$ values). The adsorption maximum of adipic acid on alumina at $\mathrm{pH} 5$ could be due to electrostatic interaction between $\mathrm{HX}^{-}$and $\mathrm{AlOH}_{2}{ }^{+}$sites. At
$\mathrm{pH}$ over 5, the amount of adsorbed adipic acid decreased monotonously with increase of $\mathrm{pH}$. FT-IR band around $1560 \mathrm{~cm}^{-1}$ is originating from the asymmetric carboxylate motions of the outersphere complex. The viscosity of PAA solution suddenly rose between $\mathrm{pH} 6$ from $\mathrm{pH} 5$ and it increased gradually at $\mathrm{pH} 6$ to 9 . Judging from the results of adipic acid adsorption on alumina, neutralization behavior of PAA solution, adsorption behavior of an acrylic resin containing a carboxylic acid, rheological behavior of suspensions and characteristics of green sheets are estimated. By the investigation using the acrylic resin $\mathrm{P}-4$, this estimation is confirmed correct. The study of a carboxylic acid of low molecular weight can be applied to that of an acrylic resin containing a carboxylic acid. From the results of adipic acid, a polymer design is considered as follows. Adsorption forms of 'tail' and 'loop' are recommended for steric stabilization of alumina particles. To adsorb on alumina strongly, a polymer should have adsorption sites where functional groups gather. As for polymerization method, block polymerization is desirable because adsorption sites and non-adsorption sites are able to be chosen optionally each. In conclusion, I found TI value of suspension is related to packing degree of green sheet. This result is important to produce water-base green sheet for high precision ceramics products.

\section{References}

1) N. M. D. Brown, R. B. Floyd and D. G. Walmsby, J. Chem. Soc., Faraday Trans., 75, 261-270 (1979).

2) F. J. Boerio and S. L. Chen, J. Colloid Interface Sci., 73, 176185 (1980).

3) D. L. Allara and J. Swalen, J. Phys. Chem., 86, 2700-2704 (1982).

4) W. G. Golden, C. Snyder and B. Smith, J. Phys. Chem., 86, 4675-4678 (1982).

5) H. K. Rao, J. M. Cases and K. S. E. Forsberg, J. Colloid Interface Sci., 145, 330-348 (1991).

6) E. Mielczarski, P. deDonato, J. A. Mielczarski, J. M. Cases, O. Barres and E. Bouquiet, J. Colloid Interface Sci., 226, 269276 (2000).

7) O. Ogbonnaya and N. Christophor, J. Colloid Interface Sci., 186, 225 (1997).

8) T. H. Ballinger, J. C. S. Wong and J. T. J. Yates, Langmuir, 8, 1676-1678 (1992).

9) W. Q. Gong, A. Parentich and L. J. Warren, Langmuir, 8, 118124 (1992).

10) R. P. Sperline and Y. Song, Langmuir, 13, 6985-6994 (1997).

11) J. Degenhardt and A. J. McQuillan, Langmuir, 15, 4595-4602 (1999).

12) D. Peak, R. G. Ford and D. L. Sparks, J. Colloid Interface Sci., 218, 289-299 (1999).

13) B. Gu, J. Schmitt, Z. Chem, L. Liang and J. F. McCarthy, Geochim. Cosmochim. Acta, 59, 219-229 (1995).

14) R. L. Frost, J. Kristof, E. Mako and J. T. Kloprogge, Langmuir, 16, 7421-7438 (2000).

15) T. V. Kumar, S. Prabhakar and G. B. Raju, J. Colloid and Interface Sci., 247, 275-281 (2002).

16) J. F. Arenas and J. I. Marcos, Spectrochim. Acta, Part A, 35A, 355 (1979).

17) O. Klug and W. Forsling, Langmuir, 15, 6961-6968 (1999).

18) I. Szaraz and W. Forsling, Langmuir, 17, 3987-3996 (2001).

19) I. Iliopoulos and R. Audebert, Polymer Bulletin, 13, 171-178 (1985).

20) K. N. Han, T. W. Healy and D. W. Feurstenau, J. Colloid Interface Sci., 44, 407 (1973).

21) G. Purcell and S. C. Sun, Trans. SME-AIME, 226, 6 (1963).

22) P. Somasundaran and K. P. Padmanabham, "Solution Chemistry of Surfactants", 2, Ed. by K. L. Mittal, Plenum Press, New York (1979) p. 777. 